\title{
INFLUENCE OF DRIVING SPEED, TERRAIN, SEAT PERFORMANCE AND VEHICLE VIBRATION CONTROL FEATURES ON VIBRATION EXPOSURE
}

\author{
Tammy Eger, ${ }^{1}$ Michael Contratto, ${ }^{2}$ Jim Dickey, ${ }^{3}$ \\ 1. Laurentian University, Sudbury, Ontario, Canada \\ 2. Caterpillar, Peoria, Illinois, USA \\ 3. University of Western Ontario, London, Ontario, Canada
}

\section{Introduction}

Previous studies have shown higher driving speeds, rough terrain and lighter haulage loads can result in higher vibration levels at the operator/seat interface during the operation of underground mining equipment [4]. Furthermore, operators of underground mining equipment are generally exposed to vibration levels above ISO 2631-1 health guidance caution zone levels [2;3]. However, the overall reduction on frequencyweighted r.m.s. acceleration at the operator-seat interface when controlling driving speed, road maintenance, seat amplification and a vehicle design feature believed to help reduce vibration transferred to the operator cab (ride control), have not been collectively examined. Therefore, controlled testing was carried out to determine the estimated $\mathrm{A}(8)$ value under different operating conditions that manipulated driving speed, haulage weight, ride control, terrain, and driving task, for two load-haul-dump haulage (LHD) vehicles.

\section{Methods}

Whole-body vibration was measured at the floor/seat interface and the operator/seat interface in accordance with ISO 2631-1 guidelines [1]. Two LHD vehicles were driven on a controlled test track by the same operator. Several variables were controlled/manipulated during the testing including driving speed (Gear; G-1, 2, 3, and auto-shift; AS), haulage (loaded bucket; unloaded bucket), ride control (RC on, off), terrain (RT rough terrain typical of a new production zone, MAIN, maintained typical of a graded surface; MT, combination of rough and maintained), driving task (F, forward, B, backward, M, mucking), and seat (NA; no amplification (optimized), A, amplification (not-tuned)). Frequency-weighted R.M.S. acceleration at the operator/seat interface was calculated in order to estimate $\mathrm{A}(8)$ values based on vibration exposure under several combinations of the variables above in order to determine predicted risk changes according to the ISO 2631-1 health-guidance caution zone.

\section{Results}

Frequency-weighted R.M.S. acceleration values at the floor/seat interface were lowest when the LHD was driven at the lowest speed, forward, over smooth terrain, with ride control on and the bucket loaded $\left(0.20 \mathrm{~m} / \mathrm{s}^{2}\right)$. The highest value occurred when the LHD was driven in the highest gear, backward, over rough terrain, with ride-control off, the bucket unloaded, and seat amplification present $\left(1.29 \mathrm{~m} / \mathrm{s}^{2}\right)$. Predicted changes to $A(8)$ value are illustrated for one of the LHD vehicles for six scenarios including driving with ride control off over rough and smooth terrain using all gears (RC OFF; MT; G1AS); driving with ride control off over rough and smooth terrain using gears 1-3 (RC OFF; MT; G1-3); driving with ride control on over rough and smooth terrain using all 
gears (RC ON; MT; G1-AS); driving with ride control on over rough and smooth terrain using gears 1-3 (RC ON; MT; G1-3); driving with ride control on over primarily maintained terrain using gears 1-3 (RC ON; Main; G1-3), and driving with ride control on over mixed terrain using gears 1-AS with no vibration amplification through the seat (RC ON; MT: G1-AS; No seat amp.).

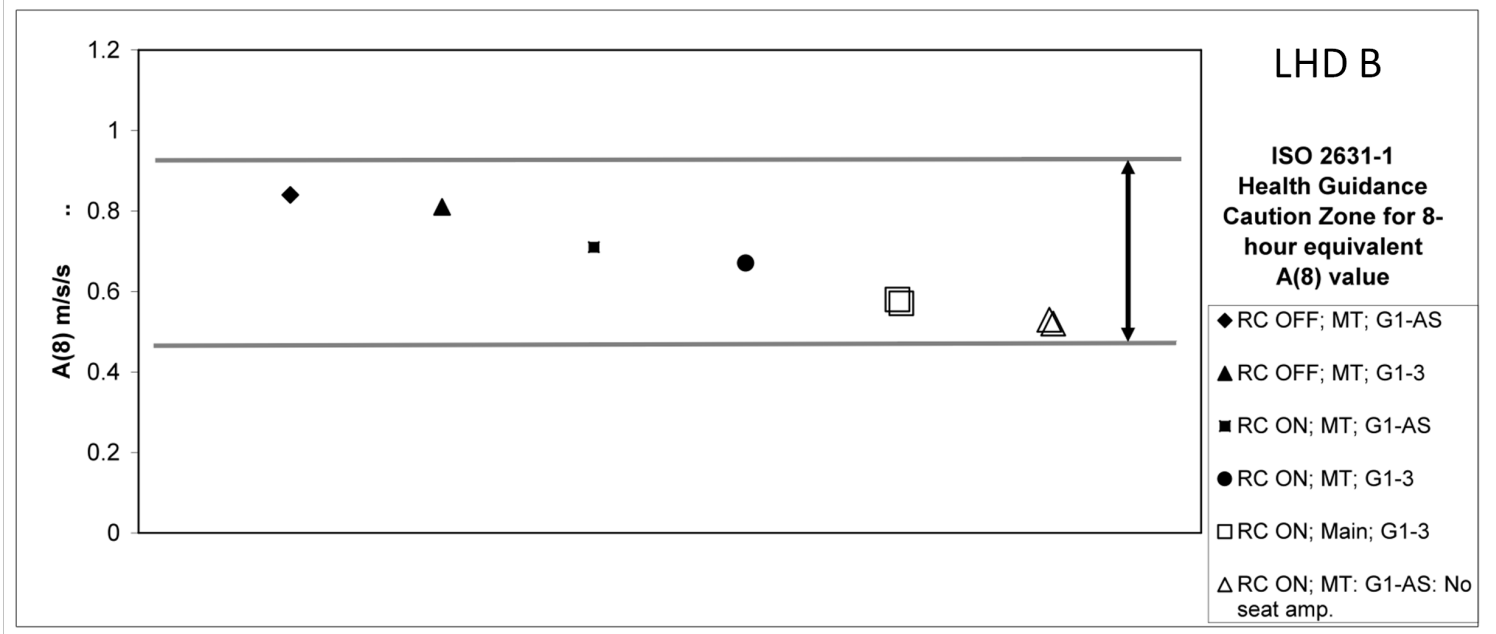

Figure 1 - A(8) values for six scenarios for one vehicles compared to ISO 2631-1 HGCZ.

\section{Discussion}

The $\mathrm{A}(8)$ decreased from $0.84 \mathrm{~m} / \mathrm{s}^{2}$ when driving with ride control off over mixed terrain using all gears to $0.53 \mathrm{~m} / \mathrm{s}^{2}$ when driving with ride control on over mixed terrain using all gears but with no vibration amplification through the seat (Figure 1). The changes did not result in operator exposure below the ISO 2631-1 HGCZ; however, a significant reduction in exposure is possible with interventions. Therefore, LHD operators need to be aware of the effects of their driving speed. Mining industry leaders need to support reasonable driving speeds for safe production, and they need to mandate comprehensive road maintenance programs to ensure rough roadbeds are repaired in a timely fashion. This study also supports the use of a feature, ride-control, designed to reduce the transmission of vibration to the operator and illustrated the importance of installing a seat in the vehicle that does not amplify vibration at the operator/seat interface.

\section{References}

1. International Organization for Standardization (1997). ISO 2631-1 Mechanical Vibration and Shock - Evaluation of Human Exposure to Whole-Body Vibration - Part 1: General Requirements. Geneva, Switzerland. Reference Number ISO 2631-1:1997(E)

2. Eger, T., Salmoni, A., Cann, A., and Jack, R. (2006) Whole-body vibration exposure experienced by mining equipment operators. Occupational Ergonomics, 6:1-7.

3. Eger, T., Stevenson, J., Boileau, P.-É., Salmoni, A. and VibRG (2008) Predictions of health risks associated with the operation of load-haul-dump mining vehicles: Part 1Analysis of whole-body-vibration exposure using ISO 2631-1 and ISO-2631-5 standards. International Journal of Industrial Ergonomics (38) 726-738.

4. Village, J., Morrison, J., and Leong, D. (1989) Whole-body vibration in underground load-haul-dump vehicles. Ergonomics, 32(10):1167-1183. 